\title{
Population genetics of sporophytic self- incompatibility in Senecio squalidus L. (Asteraceae) II: a spatial autocorrelation approach to determining mating behaviour in the presence of low $S$ allele diversity
}

\author{
AC Brennan ${ }^{1}$, SA Harris ${ }^{1}$ and SJ Hiscock ${ }^{2}$ \\ ${ }^{1}$ Department of Plant Sciences, University of Oxford, South Parks Road, Oxford OX1 3RB, UK; ${ }^{2}$ School of Biological Sciences, \\ University of Bristol, Woodland Road, Bristol BS8 1UG, UK
}

\begin{abstract}
We recently estimated that as few as six $S$ alleles represent the extent of $S$ locus diversity in a British population of the self-incompatible (SI) coloniser Senecio squalidus (Oxford Ragwort). Despite the predicted constraints to mating imposed by such a low number of $S$ alleles, $S$. squalidus maintains a strong sporophytic self-incompatibility (SSI) system and there is no evidence for a breakdown of SSI or any obvious negative reproductive consequences for this highly successful coloniser. The present paper assesses mating behaviour in an Oxford $S$. squalidus population through observations of its effect on spatial patterns of genetic diversity and thus the extent to which it is responsible for ameliorating the potentially detrimental reproductive consequences of low $S$ allele diversity in British $S$. squalidus. A spatial autocorrelation (SA) treatment of $S$ locus and allozyme polymorphism data for four loci indicates that
\end{abstract}

mating events regularly occur at all the distance classes examined from 60 to $480 \mathrm{~m}$ throughout the entire sample population. Less $S A$ is observed for $S$ locus data than for allozyme data in accordance with the hypothesis that SSI and low diversity at the $S$ locus are driving these large-scale mating events. The limited population structure at small distances of $60 \mathrm{~m}$ and less observed for SA analysis of the Me-2 locus and by F-statistics for all the allozyme data, is evidence of some local relatedness due to limited seed and pollen dispersal in $S$. squalidus. However, the overall impression of mating dynamics in this $S$. squalidus population is that of ample potential mating opportunities with many individuals at large population scales, indicating that reproductive success is not seriously affected by few $S$ alleles available for mating interactions.

Heredity (2003) 91, 502-509. doi:10.1038/sj.hdy.6800315

Keywords: sporophytic self-incompatibility; Senecio; $S$ allele; mating behaviour; spatial autocorrelation analysis

\section{Introduction}

Senecio squalidus L. (Oxford Ragwort, Asteraceae) maintains a strong sporophytic self-incompatibility (SSI) system governed by a single locus (S) (Hiscock, $2000 \mathrm{a}, \mathrm{b})$. We previously investigated the number of $S$ alleles in an Oxford population of $S$. squalidus and identified just six $S$ alleles (Brennan et al, 2002). Such a low estimate of $S$ allele number is unusual for a large natural SSI population because estimates from other species have shown that typically 20-40 $S$ alleles are maintained in natural populations with SSI (Lawrence, 2000). High numbers of $S$ alleles are usually a feature of natural self-incompatible (SI) populations since $S$ alleles are subject to strong negative frequency-dependent selection (Wright, 1939). It is likely that low $S$ allele diversity in British populations of $S$. squalidus is a consequence of a population bottleneck experienced by

Correspondence: SJ Hiscock, School of Biological Sciences, University of Bristol, Woodland Road, Bristol BS8 1UG, UK.

E-mail:simon.hiscock@bristol.ac.uk

Received 19 August 2002; accepted 4 April 2003 the species during its introduction and subsequent colonisation of Britain over the past 300 years (Harris, 2002).

SI species at evolutionary equilibrium characteristically maintain high numbers of $S$ alleles, through the interaction of mutation, drift, and negative frequencydependent selection, (Richman et al, 1996). Therefore, it follows that SSI species with few $S$ alleles may not be mating with optimal efficiency and may experience adverse fitness consequences. The threat to reproductive assurance caused by low $S$ allele number can be quantified in terms of mate availability (MA), the proportion of compatible mates in SI populations (Byers and Meagher, 1992). Reduced seed set and complete reproductive failure due to low $S$ allele number has been demonstrated in the threatened and rare Asteraceous species, Hymenoxys acualis var glabra (DeMauro, 1993), and Aster furcatus (Reinartz and Les, 1994). Similarly, low $S$ allele number has been cited as a reason for the relationship between seed set and population size in other Asteraceae, Eupatorium resinosum (Byers and Meagher, 1992) and Rutidosis leptorrhynchoides (Young et al, 2000). The findings of these studies contrast 
markedly with the apparent success of S. squalidus in establishing itself and rapidly colonising available habitats in Britain following its introduction (reviewed in Harris, 2002). In other SSI species that have experienced population bottleneck events, such as $A$. furcatus (Asteraceae), the negative reproductive consequences of low $S$ allele numbers have been offset by a breakdown of SSI leading to self-compatibility (SC), where self-seed set is possible (Reinartz and Les, 1994). SC may readily evolve from SI under altered selective conditions since any mutation that disrupts the incompatibility of pollen recognition or stigma response factors leads to self-fertile individuals (Levin, 1996). However, the hypothesis that SSI may be in the process of breaking down to SC in $S$. squalidus can be rejected since an effective SSI system operates in most wild-sampled and experimentally crossed individuals (Hiscock, 2000a,b; Brennan et al, 2002). Thus, one or more alternative features of the life history of $S$. squalidus must be maintaining effective reproduction within the framework of fully functional SSI.

Possible factors maintaining effective reproduction in S. squalidus were discussed at length by Brennan et al (2002) and can be summarised as follows: (i) inherent features of the reproductive biology of S. squalidus; (ii) increased dominance interactions between existing $S$ alleles; (iii) evolution at SI modifier loci other than the $S$ locus; and (iv) introgression of $S$ alleles from related Senecio species. Of the genetic factors considered, preliminary evidence suggests that increased dominance interactions between $S$ alleles and the activity of modifier loci probably function as simple solutions to increasing MA, while maintaining a strong SI system in S. squalidus. These possibilities are currently under investigation in further British and Sicilian S. squalidus populations. This paper will focus specifically on the role of the reproductive biology of $S$. squalidus in maintaining effective reproduction within the context of a functional SSI system.

A spatial autocorrelation (SA) methodology has been applied to study the reproductive biology of $S$. squalidus by determining the spatial structure of genetic markers in an Oxford population. SA analysis was used rather than a more traditional population genetic-based F-statistic methodology because SA methodologies are ideal for investigating small-scale spatial patterns of genetic diversity at the level of individual populations. With SA analysis, data for individuals' positions and genotypes are used, whereas F analyses deal only with gene and genotype frequencies of groups of individuals necessitating arbitrary or assumptive a priori subdivisions (Bacilieri et al, 1994; Epperson and Li, 1996). Thus, SA is a highly sensitive measure of population spatial structure even for relatively small sample sizes (Epperson, 1993, 1995; Epperson and Li, 1996).

SA has a long history of application to questions of biological interest (Sokal and Oden, 1978), while recent syntheses of population genetic theory with popularly used SA statistics (eg Moran's $I$ ) make SA an attractive alternative to traditional $\mathrm{F}$ analyses (Hardy and Vekemans, 1997). Here we have used SA analysis to gain a better understanding of within-population SSI-mediated mating dynamics in S. squalidus.

Identification of patterns of population substructure is a powerful approach for determining species-mating dynamics. Theoretical studies show that population substructure develops whenever there are limitations to gene flow through pollen or seed dispersal, unless disrupted by other processes, such as unifying selection or extinction-colonisation dynamics (Sokal and Wartenberg, 1983; Epperson, 1990). SA analysis can contribute to determining the important processes shaping the distribution of genetic diversity within populations, including levels of gene flow, which can be inferred through simulation studies (Epperson, 1995; Epperson and Li, 1997; Epperson et al, 1999). Mating systems, such as SI, tend to increase gene flow through pollen by increasing the scale of mating events when $S$ allele-mediated incompatibilities are more probable between close relatives (Levin and Kerster, 1974; Levin, 1989).

The study of local population substructure of genetic diversity in British S. squalidus is of particular interest in the context of understanding its SSI mating system. This is because population substructure represents the net effect of the interacting processes of enhanced population gene flow due to $S$-mediated incompatibilities coupled with potential mate availability limitations imposed by very few $S$ alleles. Additionally, this study represents a further development of the applications of SA analysis to biological systems, since it is the first time that the mating dynamics of an SI species has been investigated directly using $S$ locus data. We would expect to observe less spatial autocorrelation for $S$ locus data integrally associated with mating dynamics and under strong negative frequency-dependent selection both temporally and spatially relative to selectively neutral allozyme loci. Thus, a combined SA analysis including both $S$ locus and allozyme data provides a unique opportunity to test this hypothesis and potentially examine the effect that SSI mating dynamics has on other genetic diversity.

\section{Materials and methods}

\section{Plants}

A total of 24 S. squalidus seedlings (Ox1-Ox27, excluding Ox6, Ox7, and Ox12 that died) were collected from a population growing within a $0.5 \mathrm{~km}$ radius of Oxford railway station (OS grid ref.: SP505064) in March 1999 (Brennan et al, 2002; Figure 1). The positions of sampled plants were recorded on a 1:25000 scale OS map, and later converted to coordinate data to the nearest $5 \mathrm{~m}$ relative to an arbitrary reference point. Seedlings were grown and maintained in a glasshouse as described in Brennan et al (2002).

\section{$S$ genotyping}

A dominant $S$ allele was identified for each plant using a full diallele cross and analysis of fruit-set phenotypes as previously described (Brennan et al, 2002). One individual (Ox10) was found to be SC, based on intermediate levels of self-seed set. Thus, an $S$ allele could not be assigned to this plant, which was omitted from further analyses of $S$ genotypes.

\section{Multilocus allozyme genotyping}

Young leaf tissue samples were prepared using the methods of Ashton (1990). Proteins were separated by electrophoresis, on $14 \%$ starch gels in a continuous Triscitrate buffer ( $\mathrm{pH}$ 8.3) (Ashton, 1990; Glover and Abbott, 

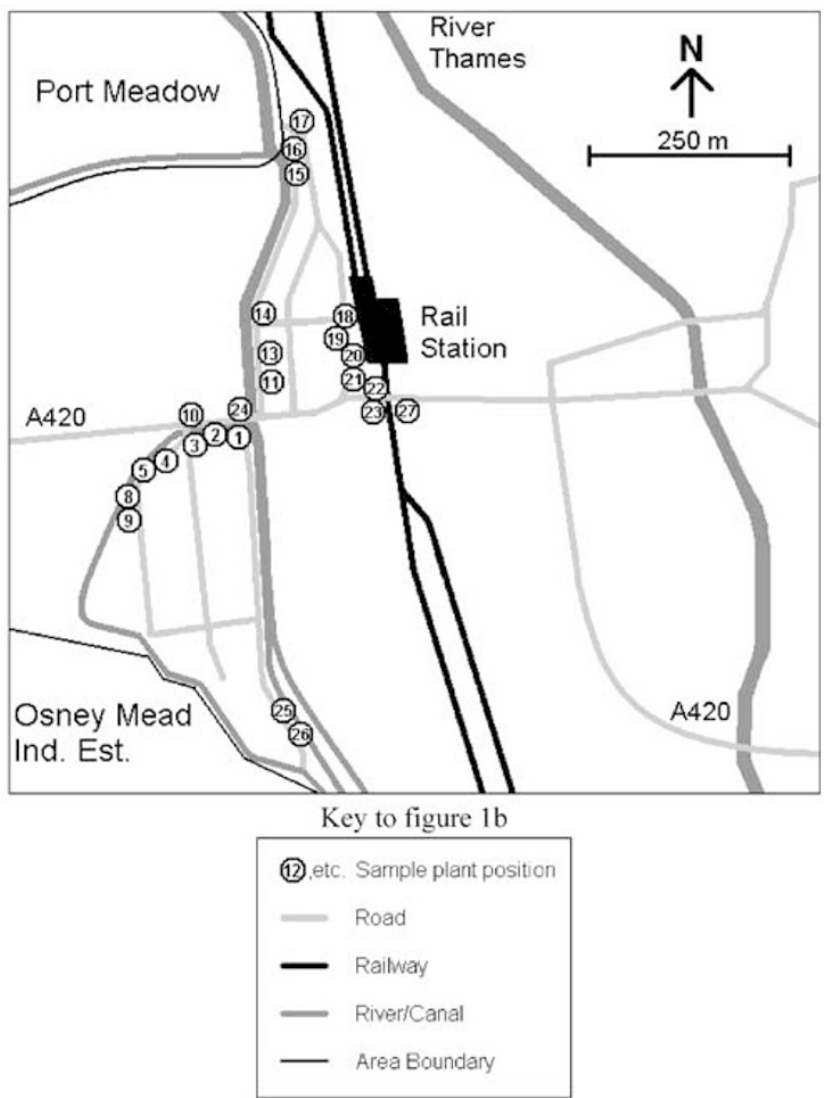

Figure 1 Outline map of Oxford Railway station area showing individual sample locations of $S$. squalidus Ox population.

1995). Gels were cut into $1 \mathrm{~mm}$ thick slices and stained for the following enzymes (Wendel and Weeden, 1990): aspartate aminotransferase (AAT, EC 2.6.1.1); aconitase (ACO, EC 4.2.1.3); $\beta$-esterase ( $\beta$-EST, EC 3.1.1.-); glutamate dehydrogenase (GDH, EC 1.4.1.2); isocitrate dehydrogenase (IDH, EC 1.1.1.42); malate dehydrogenase (MDH, EC 1.1.1.37); malic enzyme (ME, EC 1.1.1.40); 6-phosphogluconate dehydrogenase, (6-PGD, EC 1.1.1.44), phosphoglucoisomerase (PGI, EC 5.3.1.9); and phosphoglucomutase (PGM, EC 5.4.2.2). The different loci for each enzyme system and the different allozymes at each locus were identified. Loci were labelled numerically in order of decreasing migration distance from the cathode, while alleles were similarly labelled alphabetically to provide a multilocus allozyme genotype for each individual. The genetics of electrophoretic variation was confirmed in test crosses, where the allozyme genotypes of six Oxford (Ox) and five Glasgow (Gw) parental plants and up to 34 of their crossprogeny were determined and these genotype frequencies compared with expected frequencies using standard $\chi^{2}$ tests (Tables 1 and 2). Allozyme genotype data were subjected to standard population genetic analysis of linkage, Hardy-Weinberg equilibrium and intra population inbreeding coefficient, $F_{\text {is, }}$ using Genepop v.3.1d (Raymond and Rousset, 1995) and Fstat v.2.9.3 (Goudet, 1995).

\section{Spatial autocorrelation analysis}

Spatial autocorrelation analysis of polymorphic allozyme genotype and transformed $S$ locus data was performed using the program SGS v.1.0 (Degen et al, 2001).

Moran's I, a measure of spatial structure of genetic diversity at a single diallelic locus for sampled individuals within arbitrary distance classes, was calculated as follows (Sokal and Oden, 1978; Sokal and Wartenberg, 1983):

$$
I=\frac{n \sum_{i=1}^{n} \sum_{j \neq i}^{n} w_{i j}\left(a_{i}-\bar{a}\right)\left(a_{j}-\bar{a}\right)}{W \sum_{i=1}^{n}\left(a_{i}-\bar{a}\right)^{2}}
$$

where $n$ is the total number of samples; $w_{i j}=1$ or 0 , dependent on whether individuals $i$ and $j$ both belong to the same spatial interval or not; $a_{i}=1,0.5$, or 0 , dependent on whether the $i$ th individual contains 2,1 or no copies of allele $a$, and $\bar{a}$ the mean value of $a_{i}$ over all $n$ individuals.

The null expectation for Moran's I value in the absence of SA is equal to $-1 /(n-1)$ (Sokal and Wartenberg, 1983), which for this study is $-0.04(n=24)$. A Monte Carlo permutation procedure of 1000 random redistributions of genotypes over coordinates was carried out on each measured Moran's I statistic to determine their 95\% confidence intervals and probability values according to Manly (1997), also using SGS v.1.0 (Degen et al, 2001).

For each data set of genotypes considered, the null expectation for Moran's I, the measured Moran's I values, and their associated 95\% confidence intervals were plotted against distance to form correlograms or graphical representations of SA. The overall 95\% significance of each correlogram was evaluated by calculating the probability of obtaining a correlogram more extreme than the one observed according to Sidák's test, (Oden, 1984) as shown

$$
p_{(c)}=1-(1-m)^{k}
$$

\begin{tabular}{|c|c|c|c|c|c|c|c|c|c|c|c|c|}
\hline \multirow[t]{2}{*}{ Allozyme } & \multicolumn{12}{|c|}{ Parent plant crosspair } \\
\hline & $0 \times 5$ & Gw3 & $0 \times 17$ & $G w 7$ & $O x 20$ & Gw12 & $O \times 25$ & Gw2 & $O \times 26$ & Gw18 & $O \times 10^{a}$ & $0 \times 10^{a}$ \\
\hline Aat-1 & $b b$ & $a b$ & $b b$ & $a b$ & $b b$ & $a a$ & $b b$ & $b b$ & $b b$ & $a b$ & $a a$ & $a a$ \\
\hline Aco-1 & $b b$ & $a b$ & $a b$ & $a b$ & $a b$ & $a b$ & $b b$ & $a b$ & $a b$ & $b b$ & $b b$ & $b b$ \\
\hline Best-1 & $a b$ & $b b$ & $b b$ & $b b$ & $b b$ & $a b$ & $b b$ & $b b$ & $b b$ & $a a$ & $a a$ & $a a$ \\
\hline$M e-2$ & $a a$ & $a a$ & $a b$ & $a b$ & $a a$ & $b b$ & $a b$ & $a b$ & $a b$ & $a b$ & $a b$ & $a b$ \\
\hline
\end{tabular}

Table 1 Allozyme genotypes of parent plants used in test crosses of allozyme loci inheritance

Ox refers to parental plants chosen from the Oxford population described in the Materials and methods, while Gw refers to parental plants chosen from a separate Glasgow population.

aProgeny array derived from spontaneous self-seed set in the SC individual Ox10. 
Table 2 Progeny allozyme genotype frequencies and $\chi^{2}$ tests for standard Mendelian inheritance.

\begin{tabular}{|c|c|c|c|c|c|c|c|c|}
\hline \multirow[t]{3}{*}{ Allozyme } & \multirow[t]{3}{*}{ Genotype } & \multicolumn{7}{|c|}{ Parent plant crosspair } \\
\hline & & Gw3 & $0 \times 17$ & Gw12 & $O \times 25$ & Gw18 & Ox10 & $0 \times 10$ \\
\hline & & \multicolumn{7}{|c|}{ Progeny genotype frequencies } \\
\hline \multirow[t]{3}{*}{ Aat-1 } & $a a$ & 0 & 0 & 0 & 0 & 0 & \multicolumn{2}{|l|}{29} \\
\hline & $a b$ & $13 \mathrm{NS}$ & $14 \mathrm{NS}$ & 21 & 0 & $5 \mathrm{NS}$ & \multicolumn{2}{|l|}{0} \\
\hline & $b b$ & $10 \mathrm{NS}$ & 8 NS & 0 & 30 & 9 NS & \multicolumn{2}{|l|}{0} \\
\hline \multirow[t]{3}{*}{ Aco-1 } & $a a$ & 0 & $3 \mathrm{NS}$ & $4 \mathrm{NS}$ & 0 & 0 & \multicolumn{2}{|l|}{0} \\
\hline & $a b$ & $8 \mathrm{NS}$ & $13 \mathrm{NS}$ & $9 \mathrm{NS}$ & $17 \mathrm{NS}$ & $7 \mathrm{NS}$ & \multicolumn{2}{|l|}{0} \\
\hline & $b b$ & $9 \mathrm{NS}$ & $5 \mathrm{NS}$ & $7 \mathrm{NS}$ & $13 \mathrm{NS}$ & $6 \mathrm{NS}$ & \multicolumn{2}{|l|}{29} \\
\hline \multirow[t]{3}{*}{ Best-1 } & $a a$ & $\times$ & $\times$ & $\times$ & $\times$ & 0 & \multicolumn{2}{|l|}{10} \\
\hline & $a b$ & $\times$ & $\times$ & $\times$ & $\times$ & 8 & \multicolumn{2}{|l|}{0} \\
\hline & $b b$ & $\times$ & $x$ & $x$ & $\times$ & 0 & \multicolumn{2}{|l|}{0} \\
\hline \multirow[t]{3}{*}{$M e-2$} & $a a$ & 11 & $9 \mathrm{NS}$ & 0 & $9 \mathrm{NS}$ & $2^{*} \mathrm{NS}$ & $6 \mathrm{NS}$ & \\
\hline & $a b$ & 0 & $11 \mathrm{NS}$ & 27 & $17 \mathrm{NS}$ & $7^{*} \mathrm{NS}$ & $10 \mathrm{NS}$ & \\
\hline & $b b$ & 0 & $6 \mathrm{NS}$ & 0 & $4 \mathrm{NS}$ & $5^{*} \mathrm{NS}$ & $5 \mathrm{NS}$ & \\
\hline
\end{tabular}

$\mathrm{NS}=$ nonsignificant $\chi^{2}$ test result for observed genotype frequencies. ${ }^{*} \mathrm{NS}=$ nonsignificant $\chi^{2}$ test result for observed genotype frequencies when rarest genotype frequencies have been summed to expected frequency $\geqslant 5$ and degrees of freedom modified accordingly. $\times=$ allozyme locus not scored for this progeny array.

where $p_{(c)}$ is the probability of observed correlogram; $m$ the minimum individual probability value observed; and the $k$ the number of distance classes.

The sample individual coordinate data were divided into eight consecutive distance classes of $60 \mathrm{~m}(0-480 \mathrm{~m})$, which was the minimum distance class size that could be tested in order that the number of pairs of data points in each distance class averaged 27.8 (SE 2.6)-close to the minimum statistical sample size requirement for Moran's I (Waser and Mitchell, 1990).

Polymorphic allozyme loci with minimum allele frequencies of at least 0.05 were included in the SA analysis. When loci were diallelic, both alleles provide identical SA information, so each polymorphic allozyme locus yielded one correlogram upon SA analysis. Combined Moran's I values for all the allozyme loci combined were calculated by summing the numerator and denominator of equation (1) over the number of alleles tested (Streiff et al, 1998).

The same analysis was performed on the dominant $S$ genotype data coded as two alternative 'genotype' formats, $S_{\text {same }}$ and $S_{\text {diff. }}$ The $S_{\text {same }}$ data set was derived by coding the unidentified $S$ allele of each individual as the same universal recessive $S$ allele, while the $S_{\text {diff }}$ data set was derived by coding these unidentified $S$ alleles as equivalent to the $S$ allele already identified for that individual, that is, coding all individuals as $S$ homozygotes.

\section{Results}

Allozyme genotyping and population genetic analysis In all, 13 loci were identified for the nine enzyme systems investigated; one locus for each of $\beta$-EST, GDH, IDH, 6-PGD, and PGM and two loci for each of AAT, ACO, $\mathrm{ME}$, and PGI. Of these loci, seven (AAT-1, AAT-2, ACO1 , ACO-2, $\beta$-EST-1, GDH-1, and ME-2) were polymorphic. Banding patterns at four (AAT-1, ACO-1, $\beta$ EST-1, and ME-2) of these loci were reliably scored and
Table 3 Allozyme and $S$ locus genotypes of Oxford sample S. squalidus individuals

\begin{tabular}{|c|c|c|c|c|c|}
\hline $\begin{array}{l}\text { Plant } \\
\text { number }\end{array}$ & $\begin{array}{l}\text { Identified } \\
S \text { allele }\end{array}$ & $\begin{array}{c}\text { Aat-1 } \\
\text { genotypes }\end{array}$ & $\begin{array}{c}\text { Aco-1 } \\
\text { genotypes }\end{array}$ & $\begin{array}{c}\beta \text {-Est-1 } \\
\text { genotypes }\end{array}$ & $\begin{array}{c}\text { Me-2 } \\
\text { genotypes }\end{array}$ \\
\hline Ox1 & S1 & $b b$ & $b b$ & $a b$ & $b b$ \\
\hline $\mathrm{O} \times 2$ & $S 2$ & $a b$ & $b b$ & $b b$ & $b b$ \\
\hline Ox3 & $S 2$ & $b b$ & $a a$ & $b b$ & $b b$ \\
\hline Ox4 & S3 & $a b$ & $b b$ & $b b$ & $a b$ \\
\hline Ox5 & S1 & $b b$ & $b b$ & $a b$ & $a a$ \\
\hline Ox8 & $S 4$ & $b b$ & $a b$ & $a b$ & $a b$ \\
\hline Ox9 & S1 & $a b$ & $b b$ & $b b$ & $a a$ \\
\hline Ox10 & $?$ & $a a$ & $b b$ & $b b$ & $a b$ \\
\hline Ox11 & S1 & $b b$ & $b b$ & $b b$ & $a b$ \\
\hline Ox13 & $S 4$ & $a b$ & $a b$ & $a b$ & $a b$ \\
\hline Ox14 & $S 4$ & $b b$ & $b b$ & $b b$ & $a b$ \\
\hline Ox15 & $S 4$ & $a b$ & $a b$ & $b b$ & $a b$ \\
\hline Ox16 & S1 & $a a$ & $a b$ & $b b$ & $a b$ \\
\hline Ox17 & S5 & $b b$ & $a b$ & $b b$ & $a b$ \\
\hline Ox18 & $S 4$ & $b b$ & $b b$ & $b b$ & $b b$ \\
\hline Ox19 & 56 & $b b$ & $b b$ & $b b$ & $a b$ \\
\hline Ox20 & S3 & $b b$ & $a b$ & $b b$ & $a a$ \\
\hline Ox21 & $S 4$ & $b b$ & $b b$ & $b b$ & $b b$ \\
\hline Ox22 & S4 & $a b$ & $a a$ & $b b$ & $a b$ \\
\hline $\mathrm{O} \times 23$ & $S 4$ & $a b$ & $b b$ & $b b$ & $a b$ \\
\hline Ox24 & S1 & $b b$ & $a a$ & $b b$ & $b b$ \\
\hline Ox25 & $S 2$ & $b b$ & $b b$ & $b b$ & $a b$ \\
\hline Ox26 & $S 4$ & $a b$ & $a b$ & $b b$ & $a b$ \\
\hline Ox27 & S5 & $a b$ & $b b$ & $b b$ & $a a$ \\
\hline
\end{tabular}

used to generate the sample individual multilocus genotypes (Table 3). Exact tests of Hardy-Weinberg equilibrium genotype frequencies for each of the four allozyme loci indicated random mating with no population substructure in the Oxford $S$. squalidus sample (Table 4). Furthermore, $F_{\text {is }}$ values for individual and combined loci were low, indicating predominant outcrossing in the Oxford S. squalidus sample (Table 4). However, an $F_{\text {is }}$ value of 0.28 was measured at the locus Aco-1, implying an excess of homozygous genotypes, and permutation tests show the combined locus $F_{\text {is }}$ value of 0.03 to be significantly greater than zero (Table 4 ). 
Spatial autocorrelation analysis

Little evidence for significant SA was found for the allozyme data in any of the combined or individual loci analyses carried out (Figure 2; correlograms a and b). Incidences of significantly positive or negative SA statistics at a 95\% confidence level for any particular locus-distance class combination occurred at random

Table 4 Population genetic analysis of Oxford S. squalidus sample allozyme data

\begin{tabular}{llllll}
\hline Statistic & Aat-1 & Aco-1 & $\beta$-Est-1 & Me-2 & All loci \\
\hline $\begin{array}{l}\text { Frequency of } \\
a \text { allele }\end{array}$ & $0.27 \mathrm{NS}$ & $0.27 \mathrm{NS}$ & $0.08 \mathrm{NS}$ & $0.46 \mathrm{NS}$ & - \\
$F_{\text {is }}$ & 0.07 & 0.28 & 0.00 & 0.00 & $0.03^{*}$ \\
\hline
\end{tabular}

NS= nonsignificant $\chi^{2}$ test result of Hardy-Weinberg equilibrium (H-W exact test). *Significant nonzero $F_{\text {is }}$ value (95\% confidence level) based on 1000 repeat permutation tests of combined loci allozyme data.
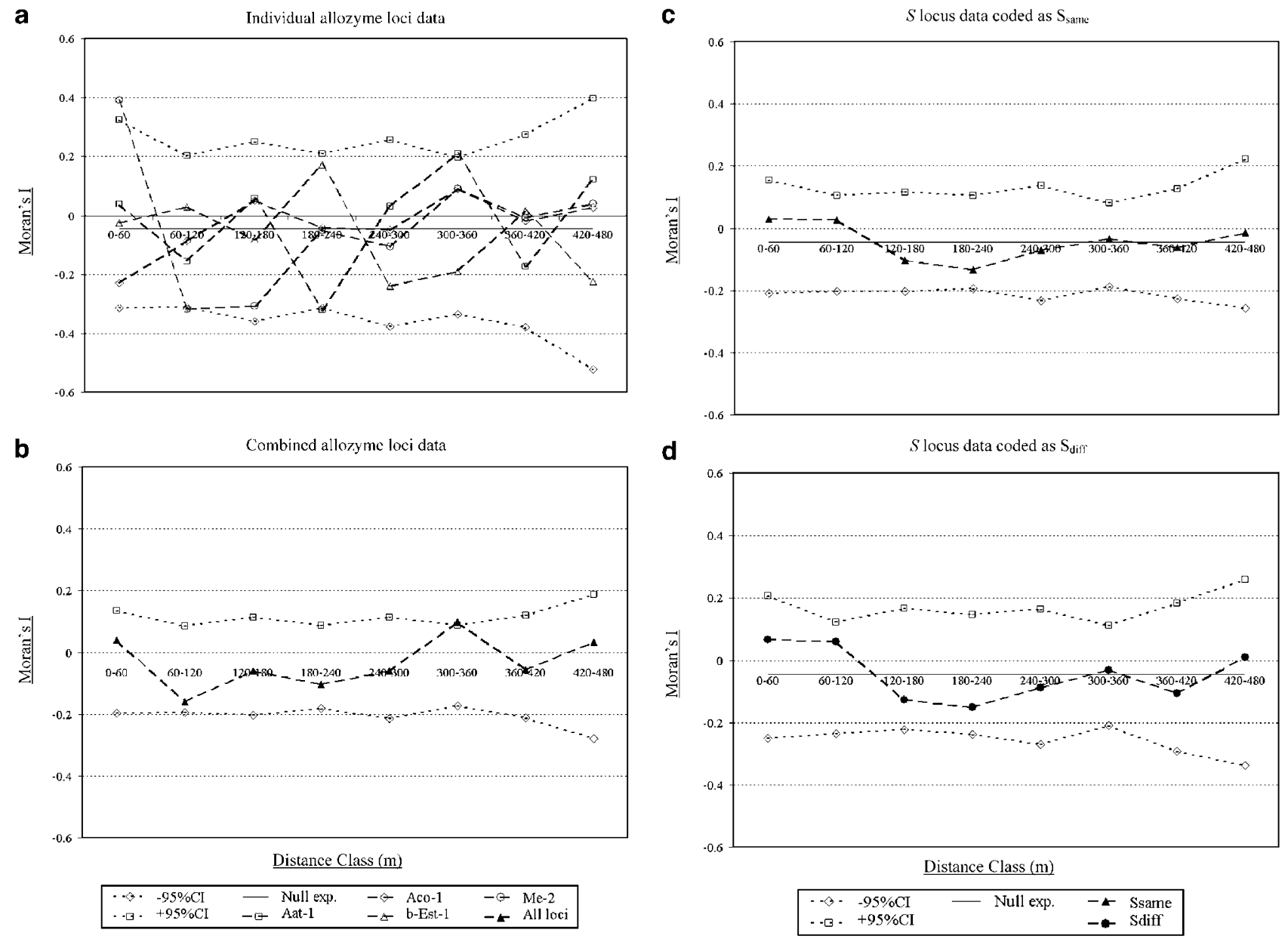

and at a frequency of 0.06 , similar to the expected 0.05 Type I error rate for multiple $P$ tests in the absence of SA. Similarly, Sidák's test probabilities for each of the correlograms indicate that they could all occur by chance in the absence of SA (Table 5). However, for the first distance class $(0-60 \mathrm{~m})$, a significantly positive Moran's I value $(I=0.39, P<0.01)$ was observed for the Me-2 locus allozyme data indicating at least some SA at this scale.

No SA was detectable for either treatment of the $S$ locus data as $S_{\text {same }}$ or $S_{\text {diff }} S$ genotypes resulted in no Moran's I values significantly greater or less than the expected null value at any of the eight distance classes (Figure 2; correlograms c, d, and notes).

\section{Discussion}

Our results demonstrate that effective reproduction in British populations of $S$. squalidus is not impeded by an SSI system operating with as few as six $S$ alleles. In the presence of SA, correlograms of Moran's I typically take the form of significantly positive values in the initial and

C

d

Figure 2 Spatial autocorrelation analysis of polymorphic allozyme loci data and $S$ allele data coded as both $S_{\text {same }}$ and $S_{\text {diff }}$ data sets for an Oxford S. squalidus sample: (a) individual allozyme loci data, (b) combined allozyme loci data, (c) $S$ locus data coded as $S_{\text {same }}$ and (d) $S$ locus data coded as $S_{\text {diff. }}$. Filled or open symbols and long-dash lines are average Moran's $I$ values for all pairs of plants within each $60 \mathrm{~m}$ distance class (see equation (1)). Open symbols and short-dash lines are average 95\% confidence limits of Moran's $I$ values based on random permutations of the data sets for pairs of plants within each $60 \mathrm{~m}$ distance class (see Materials and methods). Faint horizontal lines mark out the value for Moran's I ( $=1 /[n-1])$, expected under the null hypothesis of no spatial autocorrelation. For correlograms a and $\mathbf{b}$ representing allozyme loci SA analysis, this value is $0.043(n=24)$, while for correlograms $\mathbf{c}$ and $\mathbf{d}$ representing $S$ locus SA analysis, it is $0.045(n=23)$. Moran's $I$ values greater than these indicate positive autocorrelation at a particular distance class, values less than this indicate negative autocorrelation at that distance class (see Materials and methods). 
Table 5 Probabilities that correlograms observed for S. squalidus sample population allozyme and $S$ locus data could have occurred in the absence of spatial autocorrelation patterns

\begin{tabular}{lc}
\hline Correlogram & P-value* $^{*}$ \\
\hline Aat-1 & 0.14 \\
Aco-1 & 0.59 \\
$\beta-$ Est-1 & 0.39 \\
Me-2 & 0.06 \\
All loci & 0.34 \\
$S_{\text {same }}$ & 0.71 \\
$S_{\text {diff }}$ & 0.62 \\
\hline
\end{tabular}

* $P$-values calculated according to Šidák's technique (in Materials and methods), correlogram significant at a 95\% confidence level if $0.025>P<0.975$

small distance classes, declining to significantly negative values at larger distance classes. The Moran's I correlograms and their 95\% confidence intervals for both allozyme and $S$ loci genotype data fail to show any of these characteristic patterns associated with SA (Figure 2, correlograms a-d). Not only did these SA analyses find little evidence for significant population substructure in the Oxford population of $S$. squalidus, but they also showed that mating probably occurs regularly on scales of $0-480 \mathrm{~m}$, given the absence of significant negative SA at larger distance classes.

In particular, the SA analysis of the $S_{\text {same }}$ and the $S_{\text {diff }}$ data sets provided strong evidence for an absence of spatial structuring of $S$ genotypes in the Oxford population of S. squalidus with observed Moran's I values very close to the value expected under the null hypothesis of no SA (Figure 2, correlograms c and d). Neither the $S_{\text {diff }}$ nor the $S_{\text {same }}$ 'genotype' interpretations of the $S$ genotype data represent plausible patterns of $S$ allele diversity in SSI populations (Schierup et al, 1997). However, they can be interpreted as two alternative 'genotype' representations of the available $S$ allele data with different chances of detecting spatial structuring of $S$ alleles. When all pairs of individuals share at least one $S$ allele in common $\left(S_{\text {same }}\right)$ spatial structure is minimised, whereas when all pairs of individuals share either all or none of their $S$ alleles $\left(S_{\text {diff }}\right)$ spatial structure is maximised. The true pattern of spatial structure of the $S$ locus data for the Oxford population probably lies somewhere between these two extremes, neither of which indicated any population substructure.

Overall, the SA analysis of the allozyme loci data indicates no SA at the scale of the S. squalidus study population corroborating the $S$ locus analysis results. However, the hypothesis that the $S$ locus, under negative frequency-dependent selection, should show less SA than more selectively neutral allozyme loci is supported by the evidence for positive SA at small spatial scales for allozyme loci only.

One locus $(M e-2)$ indicated that there might be positive SA between S. squalidus individuals at spatial scales of less than $60 \mathrm{~m}$. Positive SA at small spatial scales is usually due to increased relatedness between neighbouring individuals as a consequence of limited pollen and seed dispersal (Sokal and Oden, 1978; Sokal and Wartenberg, 1983).

Additionally, the small but significantly positive $F_{\text {is }}$ value (0.03), indicative of inbreeding, is further evidence for substructure in the study population (Table 4). Inbreeding in an SI species may be an indirect consequence of matings between close relatives, and so should be influenced by local population substructure (Levin and Kerster, 1974; Levin, 1981). In SI S. squalidus, matings between close relatives are possible because of the extensive dominance interactions observed between $S$ alleles (Brennan et al, 2002). Previous studies of inbreeding in $S$. squalidus have reported a variety of $F_{\text {is }}$ values $(0-0.22)$ using other allozyme loci and populations (Abbott and Forbes, 1993; Abbott et al, 2000). Significant levels of inbreeding suggest that limited population substructure may be present in natural populations of S. squalidus in Britain.

The current SA analysis may not have detected population substructure if it is present at scales smaller than the $60 \mathrm{~m}$ distance classes considered. Distance classes below $60 \mathrm{~m}$ could not be studied for this sample population because of small sample size, necessitating a choice of distance class size containing sufficient numbers of pairs of datapoints (see Materials and methods). This small sample size is an inevitable consequence of the constraints associated with identifying $S$ locus genotypes through crossing experiments (Brennan et al, 2002).

Local relatedness in populations is an important factor to consider because it may have a large impact on reproduction at the population level. For instance, the interaction between $S$-mediated incompatibilities and population substructure has been shown to be responsible for correlations between plant proximity and reduced fertility in GSI populations of Phlox drummondii (Polemoniaceae; Levin, 1989). In British populations of S. squalidus, incompatibility between individuals due to local relatedness could be particularly prevalent because as few as six $S$ alleles are available for mating interactions (Brennan et al, 2002). Thus, further investigations of small-scale patterns of SA are needed in natural populations of $S$. squalidus with sufficiently dense sampling to allow SA analysis at distances below $60 \mathrm{~m}$.

One potential explanation for the lack of SA in the sample population is that insufficient time has passed, since the founding of the population, for spatial genetic equilibrium to have been achieved. However, this is unlikely since simulation studies show that populations rapidly develop spatial substructure in the absence of homogenising factors within very few generations and that equilibrium conditions are achieved within about 50 generations (Sokal and Wartenberg, 1983; Hardy and Vekemans, 1999). S. squalidus has been present in Oxford for the vast majority of its 300-year history in Britain (Harris, 2002), which is ample time for an equilibrium spatial genetic substructure to have developed, even if unfavourable conditions are present.

Alternatively, the lack of SA in the sample population may be the result of metapopulation dynamics of local population colonisation and extinction at a rate sufficient to disrupt the development of spatial genetic substructure (Epperson, 1990). S. squalidus occupies highly disturbed urban habitats in Britain, so metapopulation dynamics are an important feature (Brennan personal observation). However, colonisation events necessary to compensate for population extinctions indicate that British S. squalidus populations experience regular long- 
distance gene flow through both pollen and seed. Similarly, intrapopulation gene flow is likely to be sufficient to maintain adequate mate availability in the presence of few $S$ alleles.

Reproduction in $S$. squalidus appears to be little affected by low $S$ allele numbers, even though detrimental effects have been observed in other members of the Asteraceae (DeMauro, 1993; Reinartz and Les, 1994; Young et al, 2000) as discussed in the Introduction. The results of this investigation do not represent a solution to the problem of low $S$ allele number but rather our data reinforce the evidence for successful reproduction in $S$. squalidus within the context of a functional SSI system. Many factors could contribute to making S. squalidus uniquely successful at dealing with low $S$ allele diversity. Among these factors might be: its recent hybrid origin; non-SSI adaptations to a disturbed environment; or even the provision of a new niche after introduction to Britain. Tests of these fascinating hypotheses require detailed comparative studies of British $S$. squalidus' life history characteristics with these less successful Asteraceae species and also with its ancestral parental taxa in Sicily.

\section{Acknowledgements}

The work described in this paper was supported primarily by a BBSRC studentship to ACB who gratefully acknowledges additional funding from: Department of Plant Sciences, University of Oxford; a Mark Quested Award, Fishmongers' Company, London; a Margaret Pollock Award, Somerville College, Oxford; and The Lawlor Foundation, Belfast. Thanks also to: Phil Smith for care and maintenance of greenhouse plants; Dr John Brookfield; Dr Richard Abbott; and two anonymous reviewers who provided constructive criticisms to earlier drafts of this paper.

\section{References}

Abbott RJ, James JK, Irwin JA, Comes HP (2000). Hybrid origin of the Oxford Ragwort, Senecio squalidus L. Watsonia 23: 123-138.

Abbott RS, Forbes DG (1993). Outcrossing rate and selfincompatibility in the colonising species Senecio squalidus. Heredity 71: 155-159.

Ashton P (1990). Multiple origins of Senecio cambrensis Rosser and related evolutionary studies in British Senecio. PhD Thesis, University of St Andrews.

Bacilieri R, Labbe T, Kremer A (1994). Intraspecific genetic structure in a mixed population of Quercus petraea (Matl.) Leibl and Q. robur L. Heredity 73: 130-141.

Brennan AC, Harris SA, Tabah DA, Hiscock SJ (2002). The population genetics of sporophytic self-incompatibility in Senecio squalidus L. (Asteraceae) I: $S$ allele diversity in a natural population. Heredity 89: 430-438.

Byers DL, Meagher TR (1992). Mate availability in small populations of plant species with homomorphic self-incompatibility. Heredity 68: 353-359.

Degen B, Petit R, Kremer A (2001). SGS - Spatial Genetic Software: a computer program for analysis of spatial genetic and phenotypic structures of individuals and populations. $J$ Hered 92: 447-448.

DeMauro MM (1993). Relationship of breeding system to rarity in the lakeside daisy (Hymenoxys acaulis var. glabra). Conserv Biol 7: 542-550.
Epperson BK (1990). Spatial autocorrelation of genotypes under directional selection. Genetics 124: 757-771.

Epperson BK (1993). Recent advances in correlation studies of spatial patterns of genetic variation. Evol Biol 27: 95-155.

Epperson BK (1995). Fine scale spatial structure: correlations for individual genotypes differ from those for local genotypes. Evolution 49: 1022-1026.

Epperson BK, Huang Z, Li T-Q (1999). Measures of spatial structure in samples of genotypes for multiallelic loci. Genet Res Camb 73: 251-261.

Epperson BK, Li T-Q (1996). Measurement of genetic structure within populations using Moran's spatial autocorrelation statistics. Proc Natl Acad Sci USA 93: 10528-10532.

Epperson BK, Li T-Q (1997). Gene dispersal and spatial genetic structure. Evolution 51: 672-681.

Glover BJ, Abbott RJ (1995). Low genetic diversity in the Scottish endemic Primula scotica Hook. New Phytol 129: 147-153.

Goudet J (1995). FSTAT (vers. 1.2): a computer program to calculate F-statistics. J Hered 86: 485-486.

Hardy OJ, Vekemans X (1999). Isolation by distance in a continuous population: reconciliation between spatial autocorrelation analysis and population genetics models. Heredity 83: 145-154.

Harris SA (2002). Introduction of Oxford Ragwort, Senecio squalidus L. (Asteraceae), to the United Kingdom. Watsonia 24: $31-43$.

Hiscock SJ (2000a). Genetic control of self-incompatibility in Senecio squalidus L. (Asteraceae): a successful colonizing species. Heredity 85: 10-19.

Hiscock SJ (2000b). Self-incompatibility in Senecio squalidus L. (Asteraceae). Ann Bot 85 (Suppl A): 181-190.

Lawrence MJ (2000). Population genetics of the homomorphic SI polymorphism in flowering plants. Ann Bot 85 (Suppl A): 221-226.

Levin DA (1981). Dispersal versus gene flow in plants. Ann M Bot Gard 68: 233-253.

Levin DA (1989). Proximity-dependent cross-compatibility in Phlox. Evolution 43: 1114-1116.

Levin DA (1996). The evolutionary significance of pseudo-selffertility. Am Nat 148: 321-332.

Levin DA, Kerster HW (1974). Gene flow in seed plants. Evol Biol 7: 139-220.

Manly BFJ (1997). Randomization Bootstrap and Monte Carlo Methods in Biology. Chapman \& Hall, London.

Oden NL (1984). Assessing the significance of a spatial correlogram. Geogr. Anal. 16: 1-16.

Raymond M, Rousset F (1995). GENEPOP (version 1.2): population genetics software for exact tests and ecumenicism. J Hered 86: 248-249.

Reinartz JA, Les DH (1994). Bottleneck induced dissolution of self-incompatibility and breeding system consequences in Aster furcatus (Asteraceae). Am J Bot 81: 446-455.

Richman AD, Uyenoyema MK, Kohn JR (1996). Allelic diversity and gene genealogy at the self-incompatibility locus in the Solanaceae. Science 273: 1212-1216.

Schierup MH, Vekemans X, Christiansen FB (1997). Evolutionary dynamics of self-incompatibility alleles in plants. Genetics 147: 835-846.

Sokal RR, Oden NL (1978). Spatial autocorrelation in biology 1. Methodology. Biol J Linn Soc 10: 199-228.

Sokal RR, Wartenberg DE (1983). A test of spatial autocorrelation analysis using an isolation-by-distance model. Genetics 105: 219-237.

Streiff R, Labbe T, Bacillieri R, Steinkeller H, Glossl J, Kremer A (1998). Within-population genetic structure in Quercus robur L. and Quercus petraea (Matt.) Liebl. assessed with isozymes and microsatellites. Mol Ecol 7: 317-328. 
Waser NM, Mitchell RJ (1990). Nectar standing crops in Delphinium nelsonii flowers: spatial autocorrelation among plants? Ecology 71: 116-123.

Wendel JF, Weeden NF (1990). Visualisation and interpretation of plant isozymes. In: Soltis DE, Soltis PS (eds) Isozymes in Plant Biology, Chapman \& Hall: London. p 5-45.
Wright S (1939). The distribution of self-sterility alleles in populations. Genetics 24: 538-552.

Young AG, Miller BG, Gregory E, Langton A (2000). Sporophytic self-incompatibility in diploid and tetraploid races of Rutidosis leptorrhynchoides (Asteraceae). Aust J Bot 48: 667-672. 